\title{
Correction to: How socioeconomic and environmental factors impact the migration destination choices of different population groups in China: an eigenfunction-based spatial filtering analysis
}

\section{Danlin $\mathrm{Yu}^{1,2}$ (D) Yaojun Zhang ${ }^{1} \cdot$ Xiwei $\mathrm{Wu}^{1}$}

Published online: 26 February 2020

(C) Springer Nature B.V. 2020

\section{Correction to: Population and Environment https://doi.org/10.1007/s11111-020-00340-y}

The original version of this article unfortunately contained a mistake. The names of Yaojun Zhang and Xiwei Wu were inadvertently interchanged.

The original article has been corrected.

Publisher's note Springer Nature remains neutral with regard to jurisdictional claims in published maps and institutional affiliations.

The online version of the original article can be found at https://doi.org/10.1007/s11111-020-00340-y

Danlin Yu

yud@mail.montclair.edu

$\bowtie$ Yaojun Zhang

zhyaojun@ruc.edu.cn

Xiwei Wu

wuxiwei@ruc.edu.cn

1 School of Sociology and Population Studies, Renmin University of China, Beijing 100872, China

2 Department of Earth and Environmental Studies, Montclair State University, Montclair, NJ 07043, USA 